\title{
Dyspnoea in patients receiving noninvasive ventilation for acute respiratory failure: prevalence, risk factors and prognostic impact
}

\author{
A prospective observational study
}

Laurence Dangers ${ }^{1,2}$, Claire Montlahuc ${ }^{3,4}$, Achille Kouatchet ${ }^{5}$, Samir Jaber ${ }^{6,7}$, Ferhat Meziani ${ }^{8}$, Sébastien Perbet ${ }^{9,10}$, Thomas Similowski ${ }^{1,2}$, Matthieu Resche-Rigon ${ }^{3,4}$, Elie Azoulay ${ }^{11}$ and Alexandre Demoule ${ }^{1,2}$ for the REVA Network (Research Network in Mechanical Ventilation) and the Groupe de Recherche en Réanimation Respiratoire en Onco-Hématologie (GrrrOH)

@ERSpublications

Dyspnoea is frequent in patients who receive NIV in the ICU and is associated with a poorer outcome http://ow.ly/sh3Z30kaieo

Cite this article as: Dangers L, Montlahuc C, Kouatchet A, et al. Dyspnoea in patients receiving noninvasive ventilation for acute respiratory failure: prevalence, risk factors and prognostic impact. Eur Respir J 2018; 52: 1702637 [https://doi.org/10.1183/13993003.02637-2017].

ABSTRACT Dyspnoea is a frequent and intense symptom in intubated patients, but little attention has been paid to dyspnoea during noninvasive mechanical ventilation in the intensive care unit (ICU).

The objectives of this study were to quantify the prevalence, intensity and prognostic impact of dyspnoea in patients receiving noninvasive ventilation (NIV) for acute respiratory failure (ARF) based on secondary analysis of a prospective observational cohort study in patients who received ventilatory support for ARF in 54 ICUs in France and Belgium. Dyspnoea was measured by a modified Borg scale.

Among the 426 patients included, the median (interquartile range) dyspnoea score was 4 (3-5) on admission and $3(2-4)$ after the first NIV session ( $\mathrm{p}=0.001)$. Dyspnoea intensity $\geqslant 4$ after the first NIV session was associated with the Sequential Organ Failure Assessment Score (odds ratio (OR) 1.12, $\mathrm{p}=0.001)$, respiratory rate (OR 1.03, $\mathrm{p}=0.032$ ), anxiety ( $\mathrm{OR} 1.92, \mathrm{p}=0.006)$, leaks (OR 2.5, $\mathrm{p}=0.002)$ and arterial carbon dioxide tension ( $\mathrm{OR} 0.98, \mathrm{p}=0.025)$. Dyspnoea intensity $\geqslant 4$ was independently associated with NIV failure (OR 2.41, p=0.001) and mortality (OR 2.11, p=0.009), but not with higher post-ICU burden and altered quality of life.

Dyspnoea is frequent and intense in patients receiving NIV for ARF and is associated with a higher risk of NIV failure and poorer outcome.

Received: Dec 182017 | Accepted after revision: May 212018

This study is registered at ClinicalTrials.gov with identifier NCT01449331.

Copyright @ERS 2018 
Affiliations: 'Sorbonne Universités, UPMC Université Paris 06, INSERM, UMRS1158, Neurophysiologie Respiratoire Expérimentale et Clinique, Paris, France. ${ }^{2}$ Service de Pneumologie et Réanimation Médicale (Dépt "R3S"), Assistance Publique-Hôpitaux de Paris, Groupe Hospitalier Pitié-Salpêtrière Charles Foix, Paris, France. ${ }^{3}$ Service de Biostatistique et Information Médicale, Assistance Publique-Hôpitaux de Paris, Hôpital Saint-Louis, Paris, France. ${ }^{4}$ Université Paris Diderot, Sorbonne Paris Cité, INSERM, UMR-1153 (CRESS), Epidémiologie Clinique, Statistique pour la Recherche en Santé (ECSTRA), Paris, France. ${ }^{5}$ Service de Réanimation Médicale et Médecine Hyperbare, Centre Hospitalier Régional Universitaire, Angers, France. ${ }^{6}$ Dépt d'Anesthésie et Réanimation, Hôpital Saint-Eloi, Montpellier, France. ${ }^{7}$ Montpellier School of Medicine, University of Montpellier, INSERM U1046, CNRS UMR 9214, Montpellier, France. ${ }^{8}$ Service de Réanimation Médicale, Nouvel Hôpital Civil, Hôpitaux Universitaires de Strasbourg and EA 7293, Fédération de Médecine Translationnelle de Strasbourg (FMTS), Faculté de Médecine, Université de Strasbourg, Strasbourg, France. ${ }^{9}$ Réanimation Médico-Chirurgicale, CHU de Clermont-Ferrand, Clermont-Ferrand, France. ${ }^{10}$ R2D2, EA-7281, Université d'Auvergne, Clermont-Ferrand, France. ${ }^{11}$ Service de Réanimation Médicale, Hôpital Saint-Louis, Paris, France.

Correspondence: Alexandre Demoule, Service de Pneumologie et Réanimation Médicale, Groupe hospitalier Pitié-Salpêtrière, 47-83 boulevard de l'Hôpital, 75651 Paris Cedex 13, France.

E-mail: alexandre.demouledaphp.fr

\section{Introduction}

Dyspnoea is a threatening sensation that shares common neural networks and clinical features with pain $[1,2]$. In contrast with pain, which has received major attention in the intensive care unit (ICU) $[3,4]$, little attention has been paid to dyspnoea [5]. However, almost one-half of intubated patients experience dyspnoea, which they describe as intense and as one of the worst experiences of their ICU stay $[6,7]$. Dyspnoea is also associated with delayed extubation [6]. Finally, there is a body of literature suggesting that negative respiratory-related experiences could play an important role in the pathogenesis of ICU-related post-traumatic stress syndromes, thereby altering quality of life (QoL) [8].

Most data concerning dyspnoea in the ICU are derived from studies conducted in intubated patients $[5,6]$. However, a growing number of patients admitted for acute respiratory failure (ARF) are now managed without being intubated due to the increasing use of noninvasive ventilation (NIV) [9] and the potential benefit of high-flow oxygen [10].

Although dyspnoea is a warning sign of a critical threat to homeostasis [1], its prevalence, intensity and impact on outcome have not been systematically assessed in patients receiving NIV as a first-line treatment for ARF. In these patients, dyspnoea is one of the key symptoms of ARF that may also be modulated by NIV. Some data indirectly suggest that dyspnoea may be frequent and severe in patients receiving NIV and could be improved in response to NIV [11-15].

The primary objective of this secondary analysis of a prospective cohort on mechanical ventilation (MV) in 54 ICUs in France and Belgium was to quantify the prevalence and intensity of dyspnoea in patients receiving NIV for ARF, both on admission to the ICU and after the first NIV session. We also examined factors associated with dyspnoea. Finally, we investigated the impact of dyspnoea on NIV success or failure, on outcome, on QoL and on post-ICU burden.

\section{Patients and methods}

The population of this study was selected from patients included in a prospective observational study conducted in 54 French and Belgian ICUs, which were members of the REVA Network (Research Network in Mechanical Ventilation) or the FAMIREA Study Group (on improving the effectiveness of communication with the relatives of ICU patients) and which was initially designed to evaluate NIV use in terms of both frequency and indications and to assess the effects of NIV on ICU survival.

Participating centres and collaborators are listed in the acknowledgements section. The study was approved by the institutional review board of the French-language Society for Respiratory Medicine (the Sociéte de Pneumologie de Langue Française) and was registered on a publically available database (ClinicalTrials.gov, identifier: NCT01449331). Written informed consent was obtained from all patients or their relatives. Two other studies based on this cohort have been published elsewhere $[9,16]$.

\section{Study population}

Over a 2-month enrolment period between November 2010 and April 2011, each participating ICU included in the prospective cohort consecutive adults requiring ventilatory assistance (either invasive MV or NIV) for ARF, as defined by respiratory rate $>30$ cycles. $\mathrm{min}^{-1}$, or signs of respiratory distress, or arterial oxygen saturation measured by pulse oximetry $\left(\mathrm{SpO}_{2}\right)<90 \%$ on room air. For the purposes of the present post hoc study, only patients who received NIV as a first-line treatment for ARF were included. 
Patients receiving NIV for comfort care only and patients with missing data or incomplete data on dyspnoea were excluded.

\section{Data collection}

Patients were followed daily in the ICU, at hospital discharge and at 90 days post-ICU discharge (day-90). At each of these time points, the study investigators completed a standardised electronic case report form. Demographic data and medical history collected consisted of: age, gender, Simplified Acute Physiology Score (SAPS) II [17], Sequential Organ Failure Assessment Score (SOFA) [18], underlying diseases such as chronic respiratory disease (chronic obstructive or restrictive pulmonary disease, obesity, neuromuscular disease, etc.), the need for home oxygen therapy, and chronic heart failure (New York Heart Association (NYHA) grade III or IV) and immunosuppression (defined as a neutrophil count less than 1000 per $\mathrm{mm}^{3}$, malignancy treated by cancer chemotherapy, immunosuppressive therapy for solid organ transplantation, corticosteroid therapy at a daily dose of $20 \mathrm{mg}$ or more for at least 3 weeks, or AIDS). The cause of ARF was either acute-on-chronic respiratory failure (defined as respiratory failure occurring in patients with pre-existing respiratory disease), cardiogenic pulmonary oedema, or de novo ARF (defined as respiratory failure not exacerbating chronic lung disease or heart failure, also called hypoxaemic ARF).

Respiratory rate, intensity of dyspnoea and arterial blood gas values were recorded 1) at ICU admission before initiation of ventilatory support, and 2) after the first NIV session. To assess the intensity of dyspnoea, patients were asked to rate their breathing discomfort (in French "inconfort respiratoire") on a modified Borg category-ratio (1-10) scale [19] that consists of verbal descriptors linked to specific numbers, in which the spacing of the numbers and corresponding descriptors essentially provides a category scale with ratio properties. This scale ranges from zero, representing no dyspnoea, to 10, representing maximal dyspnoea. It was used to identify two groups of patients based on a dyspnoea intensity of four, qualified as "somewhat severe dyspnoea". This cut-off was based on the many similar features shared by dyspnoea and pain (noxious sensations, common pathways, similar cortical areas involved and affective dimension). A pain score of four or more is considered to be a clear indication for analgesia [20]. In the present study, a dyspnoea intensity of less than four was defined as "mild or no dyspnoea", while a dyspnoea intensity of four or more was defined as "moderate-to-severe dyspnoea" [19, 21]. The presence of air leaks and anxiety, and the prescription of analgesics (including opioids) were also recorded, as were the need for invasive MV, ICU and in-hospital length of stay, ICU mortality, in-hospital mortality and day-90 mortality.

NIV success or failure was defined as follows: patients requiring endotracheal intubation or who died during the $24 \mathrm{~h}$ following NIV discontinuation were classified as NIV failures. Patients treated with NIV until they no longer required ventilatory support were classified as NIV successes. Ninety days after ICU discharge (day-90), trained social workers coached by psychologists and sociologists of the FAMIREA study group interviewed survivors by telephone. Patients were asked to complete the 36-item Short-Form Health Survey (SF-36) to assess health-related quality of life (HRQoL), the Impact of Event Scale-Revised (IES-R) to assess post-traumatic stress disorder (PTSD) related symptoms [22, 23] and the Hospital Anxiety and Depression Scale (HADS) to quantify symptoms of anxiety and depression [24] (in that order). Lower HADS and IES-R scores indicated less post-ICU burden, but lower SF-36 scores indicated poorer HRQoL.

\section{Data quality}

An ICU physician not involved in the study resolved inconsistencies in the data entered by the investigators, based on comparison of the study case report forms with the medical charts. The database was audited by an independent check of all ICU variables on a random sample of $10 \%$ of patients.

\section{Statistical analysis}

Quantitative variables were described as median (interquartile range (IQR)) and were compared between groups using the non-parametric Wilcoxon rank-sum test or a paired Wilcoxon rank-sum test for matched data. Qualitative variables were described as n (\%) and were compared between groups using Fisher's exact test. Median ICU and in-hospital lengths of stay were estimated using a Kaplan-Meier estimator, with discharge alive as the event of interest and death as the censoring event.

Factors associated with moderate-to-severe dyspnoea on ICU admission or after the first NIV session and factors associated with NIV failure and hospital mortality were studied by multivariate logistic regression analysis. The multivariate model was built with variables that yielded p-values less than 0.05 on univariate analysis and/or that were considered to be clinically relevant. A backward stepwise selection procedure was performed with an elimination process based on p-values less than 0.05. Adjusted odds ratios (ORs) of variables present in the final model are presented with their 95\% CIs. Log-linearity was checked for 
continuous variables and non-log-linear variables were categorised. Hosmer-Lemeshow goodness-of-fit tests were computed on final models. Finally, the impact of dyspnoea on ICU mortality, HRQoL (SF-36), PTSD-related symptoms (IES-R) and symptoms of anxiety and depression (HADS) was evaluated in univariate analysis (using Fisher's exact test or a Wilcoxon test, as appropriate). Median hospital or ICU length of stay was compared using a log-rank test.

All tests were two-sided and p-values less than 0.05 were considered statistically significant. All statistical analyses were performed with R statistical software, version 3.2.0 (The R Project for Statistical Computing; www.r-project.org/).

\section{Results}

\section{Study population and prevalence of dyspnoea}

During the study period, 2367 patients requiring ventilatory support were admitted to the ICU (Figure 1). Of these, 1799 of them received invasive ventilatory support, 1203 for a nonrespiratory condition and 596 as a first-line treatment for ARF. The remaining 568 patients received NIV as a first-line treatment for ARF. Of these, 61 patients who received comfort-only NIV and 81 patients with missing or incomplete data on dyspnoea were excluded from the study. A total of 426 patients were finally assessed for dyspnoea on admission and after the first NIV session and were included in the present study. Table 1 indicates patient characteristics at the time of ICU admission. NIV interfaces and ventilator mode and settings are described elsewhere [9].

On admission to the ICU, before initiation of NIV, the median dyspnoea score was 4 (3-5) on the modified Borg scale and with a score of four or more (moderate-to-severe dyspnoea) in 234 patients (55\%). After the first NIV session, the median dyspnoea score decreased to $3(2-4)(\mathrm{p}<0.001)$ with a score of four or more in 166 patients (39\%). The median absolute variation of dyspnoea was $1(0-2)$ and was one or more points in 219 patients (51\%).

\section{Factors associated with moderate-to-severe dyspnoea on ICU admission and after the first NIV} session

Multivariate logistic regression analysis indicates that, on ICU admission, respiratory rate (cycles. $\mathrm{min}^{-1}$ ) was the only factor independently associated with moderate-to-severe dyspnoea (see Table 1 for factors associated with moderate-to-severe dyspnoea on ICU admission). Multivariate logistic regression analysis also indicates that, after the first NIV session, five factors were independently associated with dyspnoea. Four factors (SOFA, respiratory rate on ICU admission, anxiety and leaks) were associated with moderate-to-severe dyspnoea. However, patients with a high arterial carbon dioxide tension $\left(\mathrm{PaCO}_{2}\right)$ were

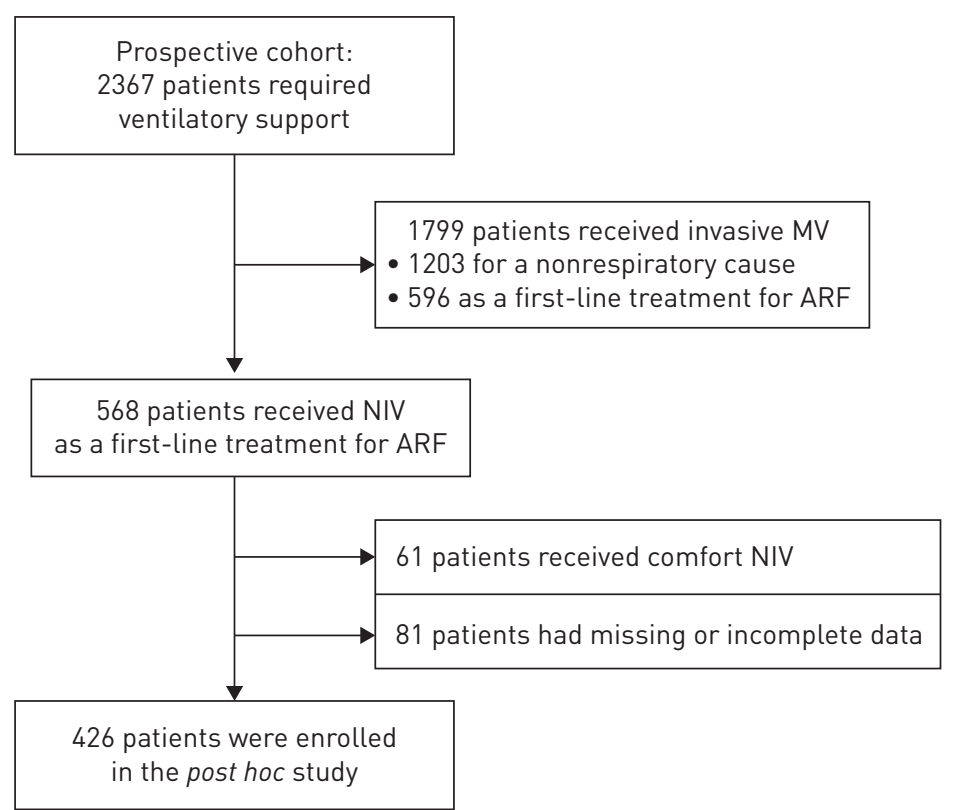

FIGURE 1 Study flow chart. MV: mechanical ventilation; NIV: noninvasive ventilation; ARF: acute respiratory failure. 
TABLE 1 Univariate analysis: factors associated with moderate-to-severe dyspnoea on admission to the intensive care unit (ICU)

\begin{tabular}{|c|c|c|c|c|}
\hline & $\begin{array}{l}\text { All patients } \\
(n=426)\end{array}$ & $\begin{array}{l}\text { Mild or no dyspnoea } \\
\qquad(\mathrm{n}=192)^{\#}\end{array}$ & $\begin{array}{l}\text { Moderate-to-severe } \\
\text { dyspnoea }(n=234)^{\pi}\end{array}$ & p-value \\
\hline \multicolumn{5}{|l|}{ Patient characteristics } \\
\hline Males & $270(63)$ & $118(61)$ & $152(65)$ & 0.48 \\
\hline $\mathrm{BMI} \mathrm{kg} \cdot \mathrm{m}^{-2}$ & $26(22-32)$ & $27(23-33)$ & $26(22-31)$ & 0.21 \\
\hline Chronic respiratory disease & $267(63)$ & $118(61)$ & $149(64)$ & 0.69 \\
\hline Chronic cardiac disease & $87(20)$ & $41(21)$ & $46(20)$ & 0.72 \\
\hline Home oxygen therapy & $88(21)$ & $33(17)$ & $55(23)$ & 0.12 \\
\hline SAPS II & $35(27-44)$ & $37(28-45)$ & $35(27-43)$ & 0.16 \\
\hline SOFA & $3(2-5)$ & $3(2-6)$ & $3(2-5)$ & 0.93 \\
\hline \multicolumn{5}{|l|}{ Cause of ARF } \\
\hline Acute-on-chronic & 251 (59) & $110(58)$ & $141(60)$ & 0.62 \\
\hline Acute cardiogenic pulmonary oedema & $58(14)$ & $26(14)$ & $32(14)$ & 1 \\
\hline De novo ARF & 116 (27) & $55(29)$ & $61(26)$ & 0.58 \\
\hline $\mathrm{PaCO}_{2} \mathrm{mmHg}$ & $53(40-71)$ & $55(40-71)$ & $52(40-70)$ & 0.57 \\
\hline $\mathrm{pH}$ & $7.34(7.27-7.40)$ & $7.33(7.27-7.40)$ & $7.34(7.27-7.41)$ & 0.45 \\
\hline
\end{tabular}

Data are presented as $\mathrm{n}(\%)$ or median (interquartile range), unless otherwise stated. BMI: body mass index; SAPS: Simplified Acute Physiology Score; SOFA: Sequential Organ Failure Assessment Score; ARF: acute respiratory failure; NIV: noninvasive ventilation; $P \mathrm{aO}_{2}$ : arterial oxygen tension; $\mathrm{FlO}_{2}$ : inspiratory oxygen fraction; $\mathrm{PaCO}_{2}$ : arterial carbon dioxide tension. ${ }^{\#}$ : Borg scale $<4$; ${ }^{\natural}$ : Borg scale $\geqslant 4$.

less likely to experience moderate-to-severe dyspnoea (see Table 2 for factors associated with moderate-to-severe dyspnoea after the first NIV session).

\section{Association between dyspnoea and NIV failure}

The NIV failure rate was $31 \%(\mathrm{n}=133)$. On multivariate logistic regression analysis (after the selection process), three factors were independently associated with NIV failure or success (see Table 3 for factors associated with NIV failure). A high SOFA score and moderate-to-severe dyspnoea after the first NIV session were associated with NIV failure, while acute-on-chronic respiratory failure as precipitating factor was associated with NIV success. Patients with acute-on-chronic respiratory failure were less likely to experience NIV failure compared to patients with de novo ARF (OR 0.40 (95\% CI 0.23-0.70), p=0.001). However, patients with moderate-to-severe dyspnoea after the first NIV session were more likely to experience NIV failure (OR 2.41 (95\% CI 1.49-3.91), p <0.0001).

\section{Associations between dyspnoea and outcome, QoL and post-ICU burden}

Moderate-to-severe dyspnoea on ICU admission was not associated with any alteration of outcome (see Table 4 for data on mortality, length of stay, quality of life and post-ICU burden). Furthermore, the SF-36 and HADS anxiety and depression sub-scores and the IES-R score did not indicate greater burden in patients with moderate-to-severe dyspnoea on ICU admission or after the first NIV session.

In contrast, on univariate analysis, moderate-to-severe dyspnoea after the first NIV session was associated with higher ICU, hospital and 90-day mortality and was also associated with longer hospital length of stay. On multivariate logistic regression analysis, three factors were independently predictive of in-hospital mortality. Two of these factors (moderate-to-severe dyspnoea after the first NIV session and SOFA score at admission) showed a positive association, while one factor, $\mathrm{PaCO}_{2}$ on ICU admission, showed a negative association (see Table 5 for the factors associated with in-hospital mortality).

\section{Discussion}

The main and major findings of this study can be summarised as follows. In a population of patients admitted to the ICU for ARF requiring NIV: 1) the level of dyspnoea was high and moderate-to-severe dyspnoea after the first NIV session was associated with anxiety; 2) moderate-to-severe dyspnoea after the first NIV session was independently associated with NIV failure and subsequent intubation; and 3) persistence of moderate-to-severe dyspnoea after the first NIV session was associated with longer length 
TABLE 2 Univariate analysis: factors associated with moderate-to-severe dyspnoea after the first noninvasive ventilation (NIV) session

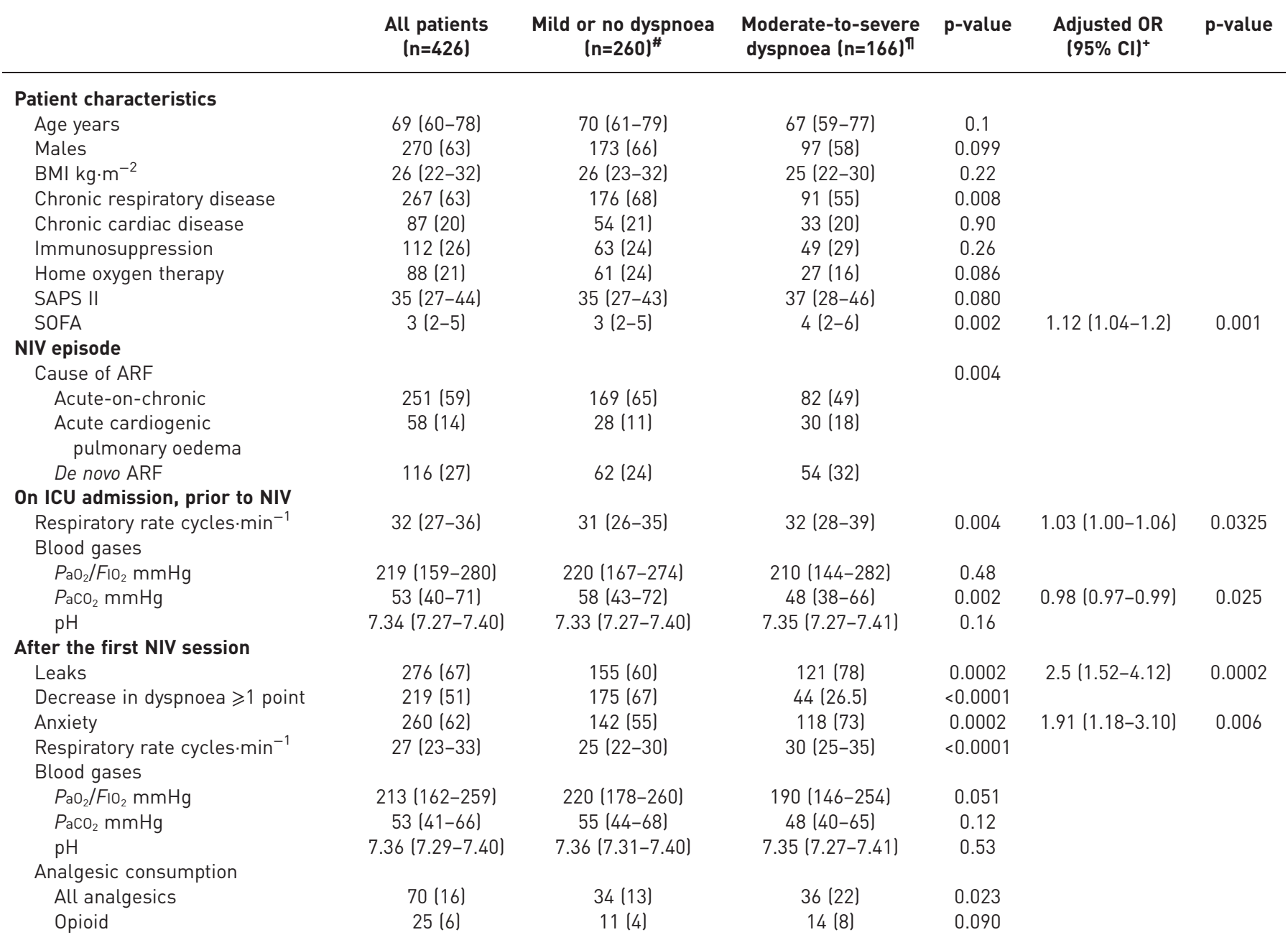

Data are presented as $\mathrm{n}(\%)$ or median (interquartile range), unless otherwise stated. BMI: body mass index; SAPS: Simplified Acute Physiology Score; SOFA: Sequential Organ Failure Assessment Score; ARF: acute respiratory failure; ICU: intensive care unit; $P_{a} 0_{2}$ : arterial oxygen tension; $\mathrm{F}_{12}$ : inspiratory oxygen fraction; $\mathrm{PaCO}_{2}$ : arterial carbon dioxide tension; OR: odds ratio. \#: Borg scale <4; ๆ: Borg scale $\geqslant 4$;

${ }^{+}$: final multivariate selected model (the following variables were included in the initial complete model: gender, age, cause of ARF, SOFA, respiratory rate on ICU admission, $\mathrm{PaCO}_{2}$ on ICU admission, anxiety and leaks). Goodness-of-fit (Hosmer-Lemeshow) $p$-value: 0.70 .

of stay and hospital mortality, but was not associated with post-ICU burden or impaired QoL. To the best of our knowledge, this is the largest study to investigate dyspnoea in a population of non-intubated patients admitted for ARF and treated with NIV. Dyspnoea has been measured as a secondary outcome in many trials evaluating the benefit of NIV in acute-on-chronic respiratory failure and acute cardiogenic pulmonary oedema [11-14], and as a primary outcome in a trial on NIV in end-of-life patients [15]. However, the prevalence of dyspnoea and its risk factors and prognostic impact have not been previously studied in such a large population.

\section{Prevalence and intensity of dyspnoea}

The prevalence of moderate-to-severe dyspnoea was 55\% at the time of ICU admission (prior to initiation of NIV) and 39\% after the first NIV session. This prevalence is similar to that reported in previous studies. $50 \%$ of intubated patients complained of dyspnoea as soon as they were able to answer symptom-related questions and the median dyspnoea score on a visual analog scale was five [6]. In trials on the efficacy of NIV in ARF that included scoring of dyspnoea, dyspnoea scores ranged from three to six on a visual analog scale [11-14] with high levels of dyspnoea in all studies. Similar pain scores would require immediate treatment and constitute a clear indication for analgesia [20]. Previous reports have suggested 
TABLE 3 Univariate analysis: factors associated with failure of noninvasive ventilation (NIV)

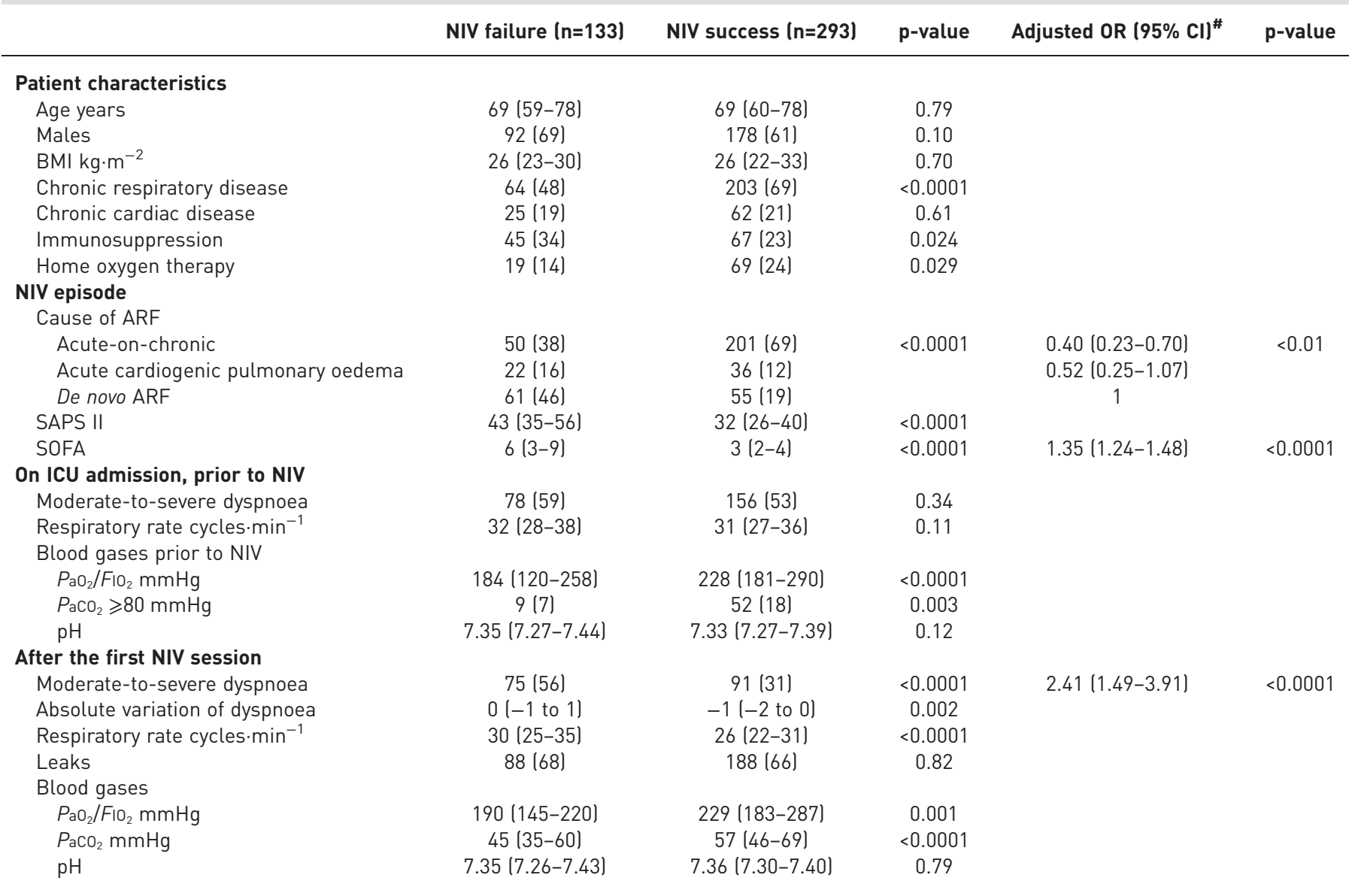

Data are presented as $\mathrm{n}(\%)$ or median (interquartile range), unless otherwise stated. BMI: body mass index; ARF: acute respiratory failure; SAPS: Simplified Acute Physiology Score; SOFA: Sequential Organ Failure Assessment Score; ICU: intensive care unit; PaO ${ }_{2}$ : arterial oxygen tension; $\mathrm{FlO}_{2}$ : inspiratory oxygen fraction; $\mathrm{PaCO}_{2}$ : arterial carbon dioxide tension; OR: odds ratio. \#: final multivariate selected model lthe following variables were included in the initial complete model: immunosuppression, home oxygen therapy, cause of $A R F$, SOFA, $P a \mathrm{aCO}_{2}$ on ICU admission prior to NIV, dyspnoea after the first NIV session, absolute variation of dyspnoea, respiratory rate after the first NIV session and leaks). Goodness-of-fit (Hosmer-Lemeshow) p-value: 0.61.

that the minimal clinically important difference (MCID) for the modified Borg scale is one point [25-27]. It is noteworthy that the first NIV session had a moderate impact on dyspnoea, as the dyspnoea score decreased by one point or more in only one-half of patients.

Although it is not surprising to observe dyspnoea before initiation of NIV in patients admitted for ARF, as dyspnoea is one of the major clinical features of ARF, we were surprised by the marked severity of dyspnoea observed in this population, even after the first NIV session. These findings suggest that dyspnoea should be actively investigated in ICU patients admitted for ARF, in the same way as pain. It must be stressed that relief of dyspnoea is an essential clinical mission that, as in the case of pain, is currently considered by some authors to be a basic human right $[28,29]$.

Theoretically, NIV can either alleviate dyspnoea due to respiratory muscle unloading [30] or exacerbate dyspnoea because of poor patient-ventilator interaction. In the present study, we observed that the median dyspnoea score decreased in response to NIV.

\section{Factors associated with dyspnoea}

Anxiety was independently associated with dyspnoea after the first NIV session, as previously reported in mechanically ventilated patients [6]. The interplay between anxiety and dyspnoea is complex with causal relationships in both directions. Anxiety, like pain, can increase dyspnoea by stimulating ventilatory drive and consequently ventilation [31]. Reciprocally, dyspnoea generates anxiety and it has been clearly demonstrated that relief of dyspnoea decreases anxiety [32]. There is now a growing body of evidence to 
TABLE 4 Outcome, quality of life (QoL) and post-intensive care unit (ICU) burden according to the severity of dyspnoea on ICU admission and after the first noninvasive ventilation (NIV) session

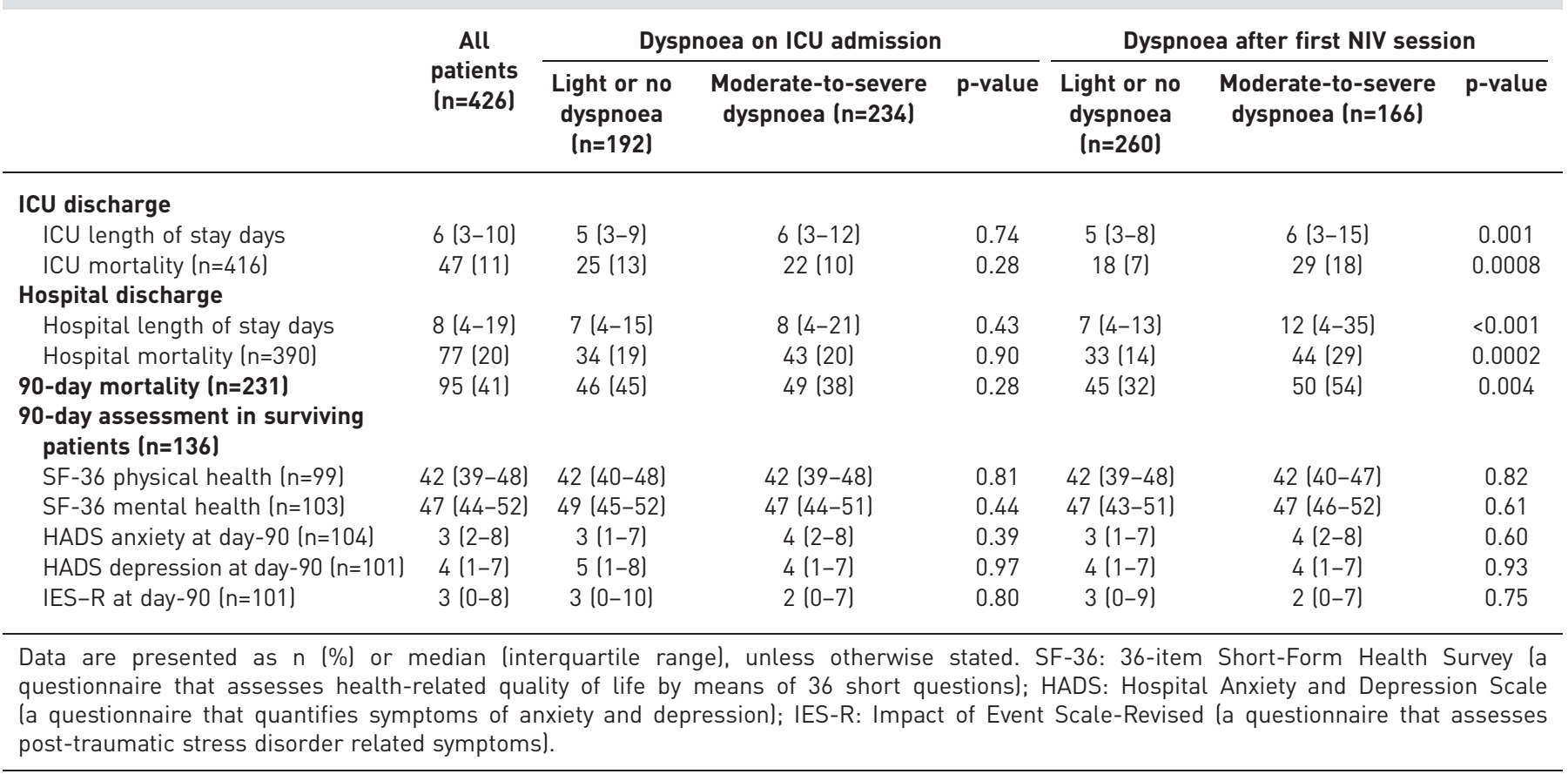

support the concept of overlap between anxiety and dyspnoea and that relief of one should improve the other $[31,33]$.

Leaks were also independently associated with dyspnoea. In NIV patients, leaks are a clearly demonstrated cause of alterations of breathing pattern and patient-ventilator asynchronies [34, 35]. In stable chronic obstructive pulmonary disease (COPD) patients receiving home NIV, adjustment of ventilator settings decreased asynchronies and leaks and improved morning dyspnoea [36]. Adjustment of ventilator settings may therefore help to relieve patients with significant dyspnoea. Similar observations have been reported in intubated patients [6].

Of note, although patients with moderate-to-severe dyspnoea were more likely to receive analgesics, including opioids, only a small proportion (16\%) of patients received such agents, which could be related to a fear of respiratory depression. However, some patients may have been deprived of a dyspnoearelieving treatment. The benefit-risk balance of these medications in patients with ARF remains unknown.

\section{NIV failure}

One of the major findings of this study is that dyspnoea, a key symptom of ARF, was associated with NIV failure. More specifically, dyspnoea after the first NIV session, but not dyspnoea on ICU admission or the absolute variation of dyspnoea, was associated with NIV failure, suggesting that improvement of dyspnoea after the first NIV session designed to treat ARF may constitute a useful marker of the quality of response to NIV. Absence of improvement of dyspnoea is also associated with treatment failure during acute exacerbations of COPD [37].

\section{Clinical outcomes}

Dyspnoea was shown to be associated with higher short-term and long-term mortality. Previous studies have established a similar link in non-critically ill patients, in whom dyspnoea is predictive of mortality and constitutes a proxy for underlying diseases, particularly heart and lung disease [38]. For instance, dyspnoea alone is a predictor of survival in patients with stable COPD [39] and in patients referred for cardiac stress testing $[40,41]$. In a more acute setting, dyspnoea is a predictor of in-hospital mortality in patients admitted for acute exacerbations of COPD [42] and patients with suspected [43] or confirmed [44] acute myocardial infarction. Finally, even in patients without previously diagnosed cardiopulmonary diseases, dyspnoea is independently associated with a higher risk of atrial fibrillation and myocardial infarction [45] and is a predictor of all-cause mortality $[45,46]$. To the best of our knowledge, this is the first study to report an association between dyspnoea after the first NIV session and a higher mortality rate in ICU patients. 
TABLE 5 Factors associated with in-hospital mortality ( $n=390)$

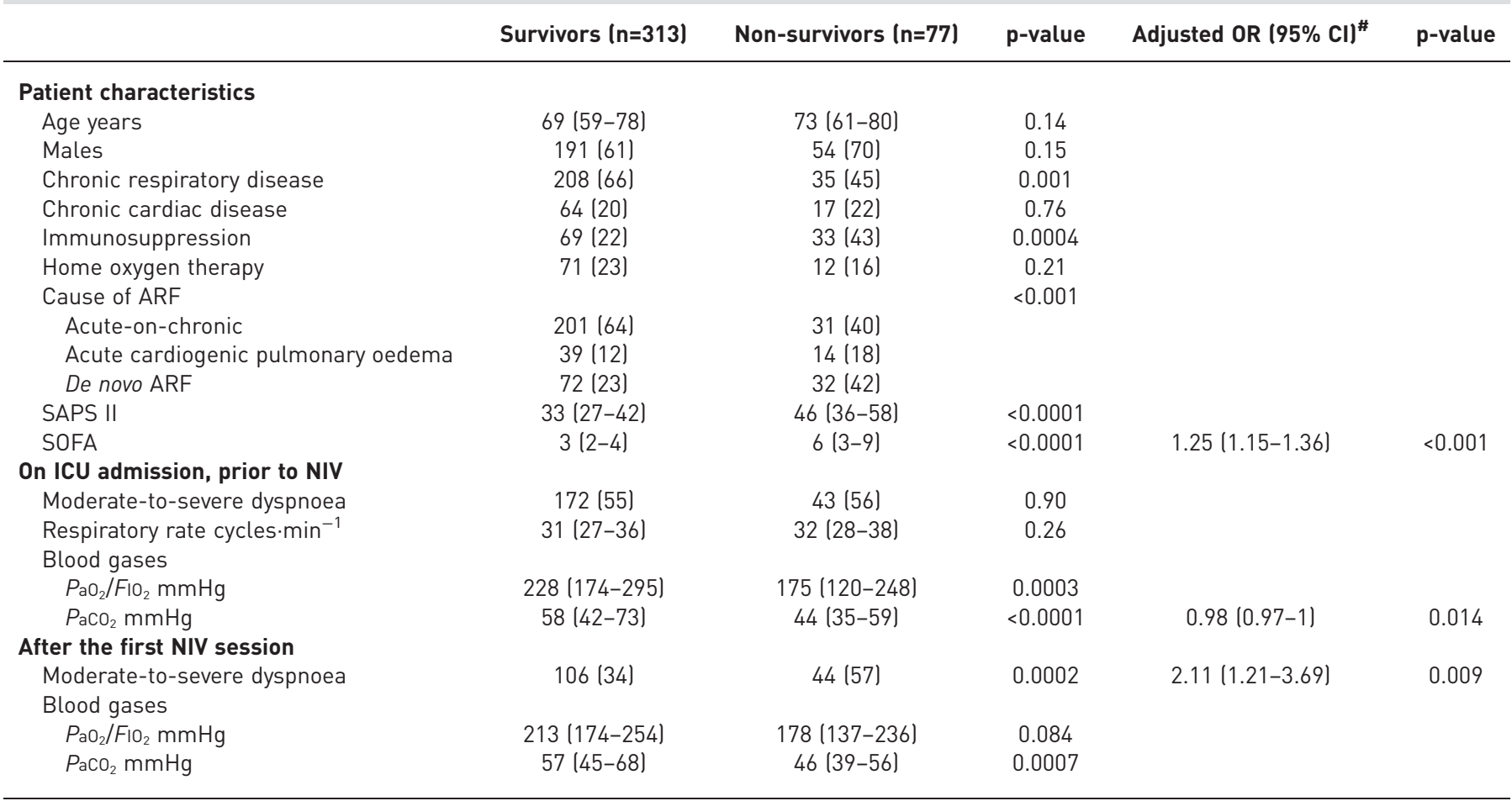

Data are presented as $\mathrm{n}(\%)$ or median (interquartile range), unless otherwise stated. ARF: acute respiratory failure; SAPS: Simplified Acute Physiology Score; SOFA: Sequential Organ Failure Assessment Score; ICU: intensive care unit; NIV: noninvasive ventilation; $\mathrm{PaO}_{2}$ : arterial oxygen tension; $\mathrm{FlO}_{2}$ : inspiratory oxygen fraction; $\mathrm{PaCO}_{2}$ : arterial carbon dioxide tension; OR: odds ratio. \#: final multivariate selected model (the following variables were included in the initial complete model: age, gender, cause of ARF, SOFA, $\mathrm{aCO}_{2}$ on ICU admission prior to NIV and dyspnoea after the first NIV session). Goodness-of-fit (Hosmer-Lemeshow) p-value: 0.59.

In contrast, no correlation was observed between dyspnoea and post-ICU burden and QoL. This negative result was all the more surprising in that dyspnoea is known to be an ICU stressor in the same way as pain and thirst [3,7] and recent data suggest that negative respiratory-related experiences can play an important role in the pathogenesis of ICU-related post-traumatic stress syndromes [47, 48].

\section{Limitations}

This study presents a number of limitations that need to be acknowledged. First, we chose to quantify dyspnoea by means of a Borg scale rather than a visual analog scale. These two scales are the two instruments most commonly used to measure dyspnoea in the ICU $[49,50]$. There are strong correlations between the two scales and their validity and reliability have been validated in critically ill patients [51, 52]. Unfortunately, the use of these tools requires patients to be alert and oriented and each instrument is only one-dimensional, measuring only the intensity of dyspnoea. Secondly, we quantified dyspnoea on only two occasions, on admission to the ICU and after the first NIV session. A longitudinal analysis based on multiple repeated measurements would provide additional results [37]. Thirdly, patients were not systematically assessed for delirium, although delirium may have an impact on assessment of dyspnoea. However, patients who were unable to provide clear and coherent answers were not included in the study (those excluded for incomplete or missing data in figure 1). Finally, this study was an additional analysis of a prospective cohort in which the first objective was not the study of dyspnoea in patients receiving NIV.

\section{Conclusion}

In conclusion, the results of this study show that dyspnoea is frequent and often intense in patients receiving NIV. Given the impact of dyspnoea on negative respiratory-related sensations and its close association with anxiety, taking the patient's perception of dyspnoea into account could help to improve the patient's immediate comfort and the quality of care provided to these patients $[5,53]$. As dyspnoea can be easily identified at the bedside, we propose that it should be monitored on a regular basis in these patients, for both human reasons and also because our study suggests that dyspnoea is a threatening signal (moderate-to-severe dyspnoea after the first NIV session was independently associated with NIV failure, 
indicating that dyspnoea could be a marker of response to NIV). Future studies should evaluate the benefit of systematic monitoring of dyspnoea in patients receiving NIV. These studies should also evaluate the benefit of treatments designed to relieve dyspnoea on patient comfort and outcome.

Author contributions: L. Dangers, E. Azoulay and A. Demoule designed the study. A. Demoule and E. Azoulay coordinated the study. A. Kouatchet, S. Jaber, F. Meziani, S. Perbet and A. Demoule were responsible for patient screening, enrolment and follow-up. L. Dangers, C. Montlahuc, M. Resche-Rigon, E. Azoulay and A. Demoule analysed the data. L. Dangers, C. Montlahuc, T. Similowski, E. Azoulay and A. Demoule wrote the manuscript. All authors had full access to all study data, contributed to drafting the manuscript or revised it critically for important intellectual content, approved the final version of the manuscript, and take responsibility for the integrity of the data and the accuracy of the data analysis.

List of contributors who included study patients: Angers University Hospital, Angers, France: A. Kouatchet, A. Mercat, S. Mortaza; Pellegrin Hospital, Bordeaux, France: F. Vargas; Saint-André Hospital, Bordeaux, France: O. Guisset; Ambroise Paré University Hospital, Boulogne Billancourt, France: L. Bodson, C. Charron; Bourg-en-Bresse Hospital, Bourg-en-Bresse, France: X. Tchenio; Bligny Medical Center, Briis-sous-Forges, France: P. Andrivet; Louis Pasteur Hospital, Chartres, France: M. Hamrouni, P. Kalfon; Antoine Béclère University Hospital, Clamart, France: O. Jacobs; Gabriel Montpied University Hospital, Clermont-Ferrand, France: B. Souweine; Hotel Dieu University Hospital, Clermont-Ferrand, France: S. Perbet, J.M. Constantin; Sud Francilien Hospital, Corbeil, France: C. Clergue; Louis Pasteur Hospital, Dôle, France: D. Perez; Raymond Poincaré University Hospital, Garches, France: J. Aboab, G. Miloud; Bicêtre University Hospital, Le Kremlin-Bicêtre, France: L. Camous, D. Osman; Bretagne Sud Hospital, Lorient, France: P. Quinio, S. Kilani; La Croix Rousse University Hospital, Lyon, France: G. Bourdin, C. Guerin; North University Hospital, Marseille, France: M. Castanier, L. Papazian; La Timone University Hospital, Marseille, France: B. Eon, M. Gainnier, D. Lambert; Sambre-Avesnois Hospital, Maubeuge, France: W. Joos; Meaux Hospital, Meaux, France: X. Forceville, J. Martin; Marc Jacquet Hospital, Melun, France: S. Jochmans; Guy de Chauliac University Hospital, Montpellier, France: P. Corne; Saint-Eloi University Hospital, Montpellier, France: J. Carr, M. Conseil, S. Jaber; André Grégoire Hospital, Montreuil, France: V. Das; Central University Hospital, Nancy, France: M. Conrad; Hôtel Dieu University Hospital, Nantes, France: N. Brule; L'Archet University Hospital, Nice, France: J. Dellamonica; La Pitié-Salpêtrière University Hospital, Paris, France: A. Demoule, M. Schmidt; University Hospital, Nîmes, France: J.Y. Lefrant; Hôtel Dieu University Hospital, Paris, France: A. Rabbat; Cochin University Hospital, Paris, France: B. Zuber, J.P. Mira; Georges Pompidou University Hospital, Paris, France: E. Guerot; Lariboisière University Hospital, Paris, France: F. Bart, M. Legrand; René Dubos Hospital, Pontoise, France: J. Richecoeur; Reims University Hospital, Reims, France: J. Cousson; Poitiers University Hospital, Poitiers, France: D. Chatellier; Pau Hospital, Pau, France: J.N. Drault, W. Picard; Tenon University Hospital, Paris, France: M. Fartoukh, J. Messika; Saint-Louis University Hospital, Paris, France: E. Azoulay, D. Schnell; Saint-Antoine University Hospital, Paris, France: E. Maury, M. Alves; Saint-Joseph Hospital, Paris, France: M. Garrouste-Orgeas, B. Misset, S. Touati; Roanne Hospital, Roanne, France: P. Beuret, X. Fabre; Roubaix Hospital, Roubaix, France: P. Herbecq; Saint-Malo Hospital, Saint-Malo, France: V. Botoc, S. Chevalier, F. Collet; Hautepierre University Hospital, Strasbourg, France: V. Castelain, R. Janssen-Langenstein; Central University Hospital, Strasbourg, France: F. Meziani, N. Dumoussaud, H. Rahmani; Versailles Hospital, Versailles, France: S. Legriel; Bretonneau University Hospital, Tours, France: E. Massere; Tourcoing Hospital, Tourcoing, France: H. Georges; Toulon Hospital, Toulon, France: J.M. Arnal; Jules Bordet Institute, Brussels, Belgium: A.P. Meert; Brugmann University Hospital, Brussels, Belgium: J. Devriendt; Saint-Pierre University Hospital, Brussels, Belgium: P. Deschamps; Ghent University Hospital, Ghent, Belgium: P. Depuyt, D. Benoit.

Conflict of interest: S. Jaber reports personal fees from Fisher and Paykel, Drager, Medtronic and Xenios, outside the submitted work. T. Similowski reports personal fees from AstraZeneca, Boehringer Ingelheim France, GSK, Lungpacer Inc, TEVA, Chiesi, Pierre Fabre and Invacare, personal fees and non-financial support from Novartis, outside the submitted work. In addition, T. Similowski has a patent "brain-ventilator interface to improve the detection of dyspnoea" licensed to Air Liquide Medical Systems and MyBrainTechnology. E. Azoulay reports grants from the French Ministry of Health, personal fees for lecturing from Alexion, MSD and Baxter, grants and non-financial support (travel expenses) from Pfizer, and personal fees for lecturing and board participation from Gilead, during the conduct of the study. A. Demoule reports personal fees and non-financial support from Medtronic, grants, personal fees and non-financial support from Philips, grants and personal fees from Resmed and Fisher and Paykel, personal fees from Baxter and Hamilton, and grants from the French Ministry of Health, outside the submitted work.

Support statement: This work was supported by a grant from the French Ministry of Health, Assistance-Publique Hôpitaux de Paris (AOM 09006) and the French Intensive Care Society. Funding information for this article has been deposited with the Crossref Funder Registry.

\section{References}

1 Parshall MB, Schwartzstein RM, Adams L, et al. An official American Thoracic Society statement: update on the mechanisms, assessment, and management of dyspnea. Am J Respir Crit Care Med 2012; 185: 435-452.

2 Dangers L, Laviolette L, Similowski T, et al. Interactions between dyspnea and the brain processing of nociceptive stimuli: experimental air hunger attenuates laser-evoked brain potentials in humans. Front Physiol 2015; 6: 358 .

3 Chanques G, Jaber S, Barbotte E, et al. Impact of systematic evaluation of pain and agitation in an intensive care unit. Crit Care Med 2006; 34: 1691-1699.

4 Payen JF, Bosson JL, Chanques G, et al. Pain assessment is associated with decreased duration of mechanical ventilation in the intensive care unit: a post hoc analysis of the DOLOREA study. Anesthesiology 2009; 111: 1308-1316.

5 Schmidt M, Banzett RB, Raux M, et al. Unrecognized suffering in the ICU: addressing dyspnea in mechanically ventilated patients. Intensive Care Med 2014; 40: 1-10. 
6 Schmidt M, Demoule A, Polito A, et al. Dyspnea in mechanically ventilated critically ill patients. Crit Care Med 2011; 39: 2059-2065.

7 Rotondi AJ, Chelluri L, Sirio C, et al. Patients' recollections of stressful experiences while receiving prolonged mechanical ventilation in an intensive care unit. Crit Care Med 2002; 30: 746-752.

8 de Miranda S, Pochard F, Chaize M, et al. Postintensive care unit psychological burden in patients with chronic obstructive pulmonary disease and informal caregivers: a multicenter study. Crit Care Med 2011; 39: 112-118.

9 Demoule A, Chevret S, Carlucci A, et al. Changing use of noninvasive ventilation in critically ill patients: trends over 15 years in francophone countries. Intensive Care Med 2016; 42: 82-92.

10 Frat JP, Thille AW, Mercat A, et al. High-flow oxygen through nasal cannula in acute hypoxemic respiratory failure. N Engl J Med 2015; 372: 2185-2196.

11 Bott J, Carroll MP, Conway JH, et al. Randomised controlled trial of nasal ventilation in acute ventilatory failure due to chronic obstructive airways disease. Lancet 1993; 341: 1555-1557.

12 Kramer N, Meyer TJ, Meharg J, et al. Randomized, prospective trial of noninvasive positive pressure ventilation in acute respiratory failure. Am J Respir Crit Care Med 1995; 151: 1799-1806.

13 Mehta S, Jay GD, Woolard RH, et al. Randomized, prospective trial of bilevel versus continuous positive airway pressure in acute pulmonary edema. Crit Care Med 1997; 25: 620-628.

14 Liesching T, Nelson DL, Cormier KL, et al. Randomized trial of bilevel versus continuous positive airway pressure for acute pulmonary edema. J Emerg Med 2014; 46: 130-140.

15 Nava S, Ferrer M, Esquinas A, et al. Palliative use of non-invasive ventilation in end-of-life patients with solid tumours: a randomised feasibility trial. Lancet Oncol 2013; 14: 219-227.

16 Azoulay E, Kouatchet A, Jaber S, et al. Noninvasive mechanical ventilation in patients having declined tracheal intubation. Intensive Care Med 2013; 39: 292-301.

17 Le Gall JR, Lemeshow S, Saulnier F. A new Simplified Acute Physiology Score (SAPS II) based on a European/ North American multicenter study. JAMA 1993; 270: 2957-2963.

18 Vincent JL, Moreno R, Takala J, et al. The SOFA (Sepsis-related Organ Failure Assessment) score to describe organ dysfunction/failure. On behalf of the Working Group on Sepsis-Related Problems of the European Society of Intensive Care Medicine. Intensive Care Med 1996; 22: 707-710.

19 Burki NK. Dyspnea. Lung 1987; 165: 269-277.

20 Barr J, Fraser GL, Puntillo K, et al. Clinical practice guidelines for the management of pain, agitation, and delirium in adult patients in the intensive care unit. Crit Care Med 2013; 41: 263-306.

21 Mahler DA, Weinberg DH, Wells CK, et al. The measurement of dyspnea. Contents, interobserver agreement, and physiologic correlates of two new clinical indexes. Chest 1984; 85: 751-758.

22 Zatzick DF, Marmar CR, Weiss DS, et al. Posttraumatic stress disorder and functioning and quality of life outcomes in a nationally representative sample of male Vietnam veterans. Am J Psychiatry 1997; 154: 1690-1695.

23 Brunet A, St-Hilaire A, Jehel L, et al. Validation of a French version of the impact of event scale-revised. Can J Psychiatry 2003; 48: 56-61.

24 Zigmond AS, Snaith RP. The hospital anxiety and depression scale. Acta Psychiatr Scand 1983; 67: 361-370.

25 Oxberry SG, Bland JM, Clark AL, et al. Minimally clinically important difference in chronic breathlessness: every little helps. Am Heart J 2012; 164: 229-235.

26 Ries AL. Minimally clinically important difference for the UCSD Shortness of Breath Questionnaire, Borg Scale, and Visual Analog Scale. COPD 2005; 2: 105-110.

27 Pan L, Guo YZ, Yan JH, et al. Does upper extremity exercise improve dyspnea in patients with COPD? A meta-analysis. Respir Med 2012; 106: 1517-1525.

28 Currow DC, Abernethy AP, Ko DN. The active identification and management of chronic refractory breathlessness is a human right. Thorax 2014; 69: 393-394.

29 Başoğlu M. Effective management of breathlessness: a review of potential human rights issues. Eur Respir J 2017; 49: 1602099.

30 L'Her E, Deye N, Lellouche F, et al. Physiologic effects of noninvasive ventilation during acute lung injury. Am J Respir Crit Care Med 2005; 172: 1112-1118.

31 Smoller JW, Pollack MH, Otto MW, et al. Panic anxiety, dyspnea, and respiratory disease. Theoretical and clinical considerations. Am J Respir Crit Care Med 1996; 154: 6-17.

32 Twibell R, Siela D, Mahmoodi M. Subjective perceptions and physiological variables during weaning from mechanical ventilation. Am J Crit Care 2003; 12: 101-112.

33 Dudley DL, Pitts-Poarch AR. Psychophysiologic aspects of respiratory control. Clin Chest Med 1980; 1: 131-143.

34 Carteaux G, Lyazidi A, Cordoba-Izquierdo A, et al. Patient-ventilator asynchrony during noninvasive ventilation: a bench and clinical study. Chest 2012; 142: 367-376.

35 Vignaux L, Vargas F, Roeseler J, et al. Patient-ventilator asynchrony during non-invasive ventilation for acute respiratory failure: a multicenter study. Intensive Care Med 2009; 35: 840-846.

36 Adler D, Perrig S, Takahashi $\mathrm{H}$, et al. Polysomnography in stable COPD under non-invasive ventilation to reduce patient-ventilator asynchrony and morning breathlessness. Sleep Breath 2012; 16: 1081-1090.

37 Kocks JW, van den Berg JW, Kerstjens HA, et al. Day-to-day measurement of patient-reported outcomes in exacerbations of chronic obstructive pulmonary disease. Int J Chron Obstruct Pulmon Dis 2013; 8: 273-286.

38 Pesola GR, Ahsan H. Dyspnea as an independent predictor of mortality. Clin Respir J 2016; 10: 142-152.

39 Nishimura K, Izumi T, Tsukino M, et al. Dyspnea is a better predictor of 5-year survival than airway obstruction in patients with COPD. Chest 2002; 121: 1434-1440.

40 Abidov A, Rozanski A, Hachamovitch R, et al. Prognostic significance of dyspnea in patients referred for cardiac stress testing. N Engl J Med 2005; 353: 1889-1898.

41 Bernheim AM, Kittipovanonth M, Scott CG, et al. Relation of dyspnea in patients unable to perform exercise stress testing to outcome and myocardial ischemia. Am J Cardiol 2009; 104: 265-269.

42 Steer J, Norman EM, Afolabi OA, et al. Dyspnoea severity and pneumonia as predictors of in-hospital mortality and early readmission in acute exacerbations of COPD. Thorax 2012; 67: 117-121.

43 Botker MT, Stengaard C, Andersen MS, et al. Dyspnea, a high-risk symptom in patients suspected of myocardial infarction in the ambulance? A population-based follow-up study. Scand J Trauma Resusc Emerg Med 2016; $24: 15$. 
44 Kirchberger I, Heier M, Kuch B, et al. Presenting symptoms of myocardial infarction predict short- and long-term mortality: the MONICA/KORA Myocardial Infarction Registry. Am Heart J 2012; 164: 856-861.

45 Santos M, Kitzman DW, Matsushita K, et al. Prognostic importance of dyspnea for cardiovascular outcomes and mortality in persons without prevalent cardiopulmonary disease: the Atherosclerosis Risk in Communities Study. PLoS One 2016; 11: e0165111.

46 Frostad A, Soyseth V, Andersen A, et al. Respiratory symptoms as predictors of all-cause mortality in an urban community: a 30-year follow-up. J Intern Med 2006; 259: 520-529.

47 Cuthbertson BH, Hull A, Strachan M, et al. Post-traumatic stress disorder after critical illness requiring general intensive care. Intensive Care Med 2004; 30: 450-455.

48 Schelling G. Effects of stress hormones on traumatic memory formation and the development of posttraumatic stress disorder in critically ill patients. Neurobiol Learn Mem 2002; 78: 596-609.

49 Spector N, Klein D. Chronic critically ill dyspneic patients: mechanisms and clinical measurement. AACN Clin Issues 2001; 12: 220-233.

50 Spector N, Connolly MA, Carlson KK. Dyspnea: applying research to bedside practice. AACN Adv Crit Care 2007; 18: 45-58.

51 Lush MT, Janson-Bjerklie S, Carrieri VK, et al. Dyspnea in the ventilator-assisted patient. Heart Lung 1988; 17: $528-535$.

52 Powers J, Bennett SJ. Measurement of dyspnea in patients treated with mechanical ventilation. Am J Crit Care 1999; 8: 254-261.

53 Chanques G, Nelson J, Puntillo K. Five patient symptoms that you should evaluate every day. Intensive Care Med 2015; 41: 1347-1350. 